\title{
O PLANEJAMENTO URBANO E AMBIENTAL NA CONSTRUÇÃO DE CIDADES SUSTENTÁVEIS: AS HORTAS URBANAS COMUNITÁRIAS EM PORTO, PORTUGAL, E BELO HORIZONTE, BRASIL
}

\author{
THE URBAN AND ENVIRONMENTAL PLANNING \\ ON BUILDING SUSTAINABLE CITIES: COMMUNITY \\ GARDENS IN PORTO, PORTUGAL, AND BELO HORIZONTE,
}

BRAZIL

v. 8, n. 2 [13]

mai/ago (2016)

Dossiê: Cidade e Natureza
Alessandra Silva Araújo Mestrado Profissional em Planejamento Territorial e Desenvolvimento Socioambiental da Universidade do Estado de Santa Catarina (PPGPLAN/UDESC) alessandrasa59@gmail.com

\section{Resumo}

A relação entre o desenvolvimento da agricultura urbana $(A U)$ e o planejamento urbano é real e sintomática, assim como a potencialidade dessa primeira em se tornar uma ferramenta para a construção de uma cidade sustentável. Essa pesquisa identifica e contrapõe os fatores que culminaram nas iniciativas de implantação de hortas comunitárias na cidade de Porto, Portugal, e Belo Horizonte, Brasil, ressaltando a influência dos processos de planejamento das cidades em seu surgimento e as maneiras como elas vem se apropriando do conceito de sustentabilidade. Verificou-se que há uma diferença entre a forma como o planejamento urbano, nos dois casos, engloba as práticas de $A U$, e que as pontes entre ambos, feitas através das práticas de planejamento ambiental, mostraram-se incipientes, o que dificulta o objetivo do planejamento em tornar-se um catalizador para uma cidade sustentável.

\section{Palavras-Chave}

Agricultura urbana. Belo Horizonte. Hortas. Porto. Planejamento ambiental. Planejamento urbano.

\begin{abstract}
The relationship between the development of urban agriculture (UA) and urban planning is real and symptomatic, besides the potentiality of the urban agriculture to become a tool to the construction of a sustainable city. This research identifies and compares the factors that culminated in community gardens in the city of Porto, Portugal, and Belo Horizonte, Brazil, emphasizing the influence of the planning process on the emergence of those gardens, and the different ways the concept of sustainability has been appropriated by them. It was found that there is a difference between the treatment urban planning gives to UA in both cities, and that the link between UA and Urban Planning enabled by the environmental planning techniques
\end{abstract}


were incipient in both of them - besides their significant differences and peculiarities-, a factor that hinders the aim of turning urban planning into a catalyzer to a sustainable city.

\section{Keywords}

Urban agriculture. Community garden. Belo Horizonte. Porto. environmental planning. urban planning.

\section{Introdução}

Pelas ruas da cidade do Porto, Portugal, mesmo em regiões bem próximas ao centro histórico da cidade, é possível avistar espaços verdes cultivados, seja por uma unidade familiar de poucos membros, ou hortas maiores que aparentam ser de gestão não circunscrita a uma só família. Essa realidade até o momento não se assemelha à da cidade de Belo Horizonte, na qual as hortas, apesar de presentes, não são avistadas em regiões centrais com frequência e em tão grande número.

Essa distinção entre as duas realidades leva a pensar que as diferentes formas de urbanização e de apropriação do espaço culminaram em maneiras também diferenciadas de inserção das hortas em meio urbano, o que poderia apontar para a relação entre sua existência e as políticas de gestão do território. Para se contemplar essa indagação, torna-se necessário então compreender a realidade dessas iniciativas quando vistas sob o ponto de vista político e social da ocupação do espaço, para então conhecer quais os fatores que culminaram em sua implantação e persistência.

Segundo Oliveira (2013), embora o cultivo de hortas no Brasil seja uma herança portuguesa introduzida desde a época da colonização, houve diferenciações entre o modo de fazê-las nos dois países. O autor menciona que na Península Ibérica as terras onde eram cultivadas pertenciam a monges ou ordens religiosas, mas em alguns casos eram arrendadas a terceiros, sendo que a produção era voltada principalmente para o abastecimento de feiras e mercados (OLIVEIRA, 2013). Assim, as hortas que se localizavam cada vez mais próximas às cidades e serviam para facilitar a remessa de alimentos, terminavam por suavizar a distinção marcante entre campo e cidade, uma vez que penetravam cada vez mais no tecido urbano (OLIVEIRA, 2013). No Brasil, entretanto, as hortas sempre se voltaram mais marcadamente para a complementação alimentar ou autoconsumo dos que a cultivavam. E, enquanto em Portugal a produção se dava de maneira intensiva, no Brasil isso não ocorreu devido a alguns empecilhos, como a mão de obra escassa, por exemplo. Além disso, no Brasil as hortas seguiam as indicações de sistemas úmidos, se localizando em terrenos potencialmente favoráveis ao plantio extensivo de hortaliças e era praticada essencialmente pela classe média, que tinha maior contato com a cultura portuguesa (OLIVEIRA, 2013). Enfim, não só o ato de se cultivar como também alguns traços da maneira de se fazer a agricultura urbana no Brasil, como a forma de ordená-la, por exemplo, remete à herança lusíada (OLIVEIRA, 2013). 
Considerando-se a relevância da relação existente entre o desenvolvimento da agricultura urbana comunitária e o planejamento urbano, este artigo é fruto de uma pesquisa que buscou compreender de que forma as políticas oficiais de planejamento da cidade do Porto, em Portugal, e Belo Horizonte, Brasil, estão se vinculando às práticas de agricultura urbana comunitária ali desenvolvidas. Objetivou-se avaliar se as hortas poderiam estar contribuindo para a configuração dessas cidades como sustentáveis e diagnosticar os principais desafios a serem superados para tal finalidade.

Slocombe (1993) defende que a única maneira de o planejamento urbano se mover em prol da sustentabilidade é se integrando ao planejamento ambiental, já que o primeiro é fraco na abordagem ecológica, enquanto o segundo se atenta para as demandas ambientais locais. Sendo assim, no contexto que se dá essa pesquisa, verificou-se como essa ligação entre os "dois planejamentos" poderia se dar através das hortas urbanas comunitárias.

Para auxiliar na análise sobre a forma de tratamento da AU pelos planos de gestão do território das cidades em estudo, utilizaremos a definição de Quon (1999) para as categorias de postura que as cidades podem apresentar diante das atividades, sendo essas positiva, neutra ou negativa. A primeira pode ser resumida pela aceitação e reconhecimento da AU pela cidade, em que a agricultura é vista uma forma possível de uso do solo. A segunda configura uma falta de consciência sobre as consequências negativas e positivas da AU e que a faz ser ignorada nos planos para a cidade. E a terceira, vê a AU como negativa, não a reconhecendo como um uso de solo possível, o que reforça os desafios antes mencionados, desestimulandoa, ou mesmo proibindo suas ações, a fim de aboli-las (QUON, 1999).

Os estudos de caso a seguir expõem como esse envolvimento se dá nas cidades estudadas, de forma a verificar como o planejamento urbano tem agido como catalizador das atividades de agricultura urbana ( $\mathrm{AU}$ ) através do planejamento ambiental, colocando-se a serviço da sustentabilidade.

\section{Metodologia}

Para a elaboração desta pesquisa realizou-se um estudo de caso comparativo, que, de acordo com Günther (2006), pode ser entendido como um método que preza pelo entendimento de um fenômeno em determinada situação. Apesar de necessitar uma atenção maior para a possibilidade de generalizações, o estudo de caso refere-se à restrição da coleta de dados e sua análise a uma situação específica, mas, buscando a partir de um exemplo, contribuir para a definição de um fenômeno mais vasto (VOGT, 1993 apud GÜNTHER, 2006). Sendo assim, esta pesquisa buscou, a partir da comparação entre os dois casos, apontar tendências, discrepâncias, e ações positivas que poderiam ser permutadas entre as realidades, fazendo assim, com que a experiência positiva de um caso possa contribuir com as ações em decorrência no outro e contribuir para o que, em geral, se tem notado sobre essa relação em outros locais e as tendências percebíveis sobre ela.

(c) Urbana: Rev. Eletrônica Cent. Interdiscip. Estud. Cid Campinas (SP) V.8, n.2 [13] $\quad$ p.190-209 ISSN 1982-0569 
A coleta de dados se baseou na realização de entrevistas semiestruturadas com agentes-chave ligados à realização de agricultura urbana comunitária em cada município e na análise do diagnóstico dos planos prospectivos de política para o território e/ou a legislação que os rege, sendo o Regulamento do PDM (Plano Director municipal) para o Porto e, para Belo Horizonte, o Plano Diretor de Belo Horizonte (PDBH) e o Plano diretor de desenvolvimento integrado da região metropolitana de Belo Horizonte (PDDI/RMBH).

O critério para a escolha dos entrevistados foi de seu reconhecimento como uma iniciativa de $\mathrm{AU}$ oficial no local em que se desenvolve. Considerando que muitas atividades de AU comunitária são realizadas, mas não são incorporadas em bases de dados, há certa dificuldade em contatar seus responsáveis e tomar conhecimento das práticas adotadas. Em ambos os locais o ponto de partida para a identificação das iniciativas foram os movimentos de articulações sobre a AU local. Em Porto, esse reconhecimento se deu através da plataforma PORTAU - Portal da Agricultura Urbana e Peri-urbana, iniciativa da Rede Portuguesa de Agricultura Urbana e Peri-urbana (RAU), e em Belo Horizonte através da plataforma online da AMAU ${ }^{1}$ - Articulação Metropolitana de Agricultura Urbana. A partir das atividades listadas em ambas se chegou a outras que por ventura não estavam listadas, mas são ainda consideradas relevantes - pelos próprios agricultores urbanos - no movimento local das hortas urbanas. Outro critério de escolha das hortas pesquisadas foi o nível de intervenção da prefeitura em seu surgimento e apoio. Foram estudadas hortas que surgiram de iniciativas comunitárias e apenas por elas se sustentam, e aquelas que tiveram ou ainda tem alguma relação com a prefeitura, seja relativo à posse do terreno, financiamento ou qualquer outra. Foram realizadas 5 (cinco) entrevistas em cada cidade, amostra essa que foi essencialmente definida pelo número de iniciativas listadas nas plataformas mencionados, que poderiam estar, a princípio reduzidas em vista do total daquelas potencialmente existentes. Contudo, apesar de estarem em número reduzido, percebeu-se que as respostas dos entrevistados apresentavam uma tendência, considerando-se, então, que as entrevistas realizadas forneceram a base de informações suficiente para se chegar à conclusão da pesquisa. Como última etapa metodológica, foi realizada a análise dos planos diretores, de forma a compreender a visão fundamental desses sobre a AU e suas políticas em relação a ela.

\section{Resultados}

Por que ninguém fala nada da agricultura? Por que a agricultura tem que ser marginalizada? Tem que ser as grandes agriculturas, grandes plantações? Enchem os

\footnotetext{
${ }^{1}$ AMAU - Articulação metropolitana de agricultura urbana. Disponível em <www.amau.org.br>. Acesso em: 23 set. 2016
}

(c) Urbana: Rev. Eletrônica Cent. Interdiscip. Estud. Cid Campinas (SP) $\quad$ v.8, n.2 [13] $\quad$ p.190-209 $\quad$ ISSN 1982-0569 
"CEASA ${ }^{2}$ da vida" e a gente também não pode plantar, comer? [Membro de uma horta comunitária de Belo Horizonte, Outubro de 2014].

Os dois casos serão tomados separadamente a seguir, salientando que procurou-se caracterizar o meio em que surge o discurso da sustentabilidade aplicada através AU para compreender como o planejamento das cidades poderia se juntar a tal prática confluindo para interesses comuns.

\section{Regulamento do "Plano Director Municipal" e hortas no Porto}

As entrevistas realizadas no município do Porto apresentaram aspectos comuns que configuram a prática de AU local. As motivações que levaram a tais iniciativas, apontadas pelos entrevistados, são relativas ao resgate da relação com a natureza e o campo, à "limpeza" física de espaços verdes sem uso, à criação de uma comunidade local, ao apoio à agricultura biológica e à permacultura, às práticas de lazer, à atenuação da renda familiar por não precisarem comprar determinados alimentos -, e uma das iniciativas apontou para o combate às necessidades sociais e econômicas como motivação principal.

Assim, as práticas que se configuram como hortas pedagógica, comunitário-sociais e de recreio, tem como visão conjunta, ou seja, como condição definitiva para a qual estão trabalhando para alcançar, um estado no qual haja uma comunidade urbana sustentável que conheça os ciclos da natureza, que atinja uma mudança de consciência sobre seu modo de vida, de pensar e de consumir, que apoie os pequenos produtores, que deixe de depender de grandes superfícies, que possua um espaço de lazer, que conheça a origem de seu alimento e que tenha meios de complementar sua alimentação. As iniciativas, que viram na AU a possibilidade de tal mudança de pensamento, contam ou contaram em algum momento com outros projetos que corroboram os mesmos benefícios finais que conferem à agricultura. As iniciativas que não contavam com outros projetos possuíam como principal objetivo o lazer ou o suprimento de necessidades. Assim, verificou-se que o conhecimento de determinado terreno disponível e a possibilidade, digamos, facilitada de acessá-lo, juntamente com sua satisfatória localização e qualidade, foi considerada pelos entrevistados como um fator fundamental capaz de permitir a atividade. Ou seja, a disponibilidade e acessibilidade ao terreno tanto inspirou novas formas de se alcançar um objetivo como determinou qual seria essa forma.

O apoio da administração municipal foi percebido em algumas iniciativas, e se relaciona principalmente ao terreno, seja em seu arrendamento ou na possibilidade de utilização temporária pelos agricultores. O subsídio financeiro ou demais formas de apoio não foram

2 Os CEASAs (Central de abastecimento) são centros de comercialização e abastecimento do mercado atacadista de gêneros alimentícios dos estados brasileiros.

(c) Urbana: Rev. Eletrônica Cent. Interdiscip. Estud. Cid Campinas (SP) $\quad$ v.8, n.2 [13] $\quad$ p.190-209 ISSN 1982-0569 
mencionados. Nos casos em que não ocorreu qualquer parceria com a câmara não foi tido como necessário informar a ela sobre o desenvolvimento da atividade.

Pode-se dizer que os problemas ambientais que acometem a cidade e que foram levantados pelos entrevistados foram diversos e muitos se esbarram naqueles que poderiam ser, de alguma forma, mitigados pelas práticas de AU, porém não se limitando a esses. Contudo, não se notou um reconhecimento da relação entre esses problemas e a finalidade pela qual os indivíduos vinham praticando a AU. Isto é, apesar de essa prática poder ser vista como uma ferramenta que combate os problemas ambientais levantados, os entrevistados não mencionaram praticá-la com essa finalidade. Isso apontou para um descolamento entre que podia ser individualmente exercitado e uma política mais abrangente. A AU toma, nesse sentido, aplicações mais restritas e não necessariamente de articulação global. Em contrapartida, quando perguntados sobre a necessidade de um aumento do número de hortas urbanas na cidade, eles responderam positivamente, alegando, no geral, que "Quanto mais [hortas] melhor", além de ter atribuído a responsabilidade de criar tais hortas à câmara ou demais agências governamentais, mas sempre com a participação e apoio das comunidades e outros atores sociais.

Em suma, podem ser ressaltados quatro principais aspectos das entrevistas realizadas em Porto: a) as iniciativas possuem uma finalidade relacionada principalmente à criação de uma comunidade urbana sustentável, os demais aspectos mencionados se incluem no que seria característico desta comunidade, b) a existência de um terreno inspirou, corroborou e definiu a atividade que levaria à construção de tal comunidade, c) se a iniciativa não necessitou de apoio - financeiro ou não - de órgãos governamentais, não foi tido como necessário informar à câmara sobre sua ocorrência e d) o desenvolvimento da iniciativa não se incorporou a uma rede globalizada de $\mathrm{AU}$ no que tange aos benefícios socioambientais diversos que essa pode proporcionar.

O Plano Director Municipal, doravante PDM, se dá sobre o abrigo do Regime jurídico dos instrumentos de gestão territorial (RJIGT), e é regulamentado por legislação específica, a qual descreve os princípios dos planos municipais e os quais os planejadores devem seguir. Esse regulamento prevê e define categorias e subcategorias de uso do solo que são dividas entre o chamado "solo urbanizado" e "solo afeto à estrutura ecológica". A estrutura ecológica (EE), segundo Ferreira, é um instrumento do planejamento ambiental e de ordenamento do território que tem a função de conduzir o uso antrópico nesse último (FERREIRA, 2010). Ela

tem como objetivos a preservação e a promoção das componentes ecológicas e ambientais do território concelhio, assegurando a defesa e a valorização dos elementos patrimoniais e paisagísticos relevantes, a proteção de zonas de maior sensibilidade biofísica e a promoção dos sistemas de lazer e recreio. Artigo 420, 1 . Regulamento do PDM, 2012.

(c) Urbana: Rev. Eletrônica Cent. Interdiscip. Estud. Cid Campinas (SP) V.8, n.2 [13] $\quad$ p.190-209 ISSN 1982-0569 


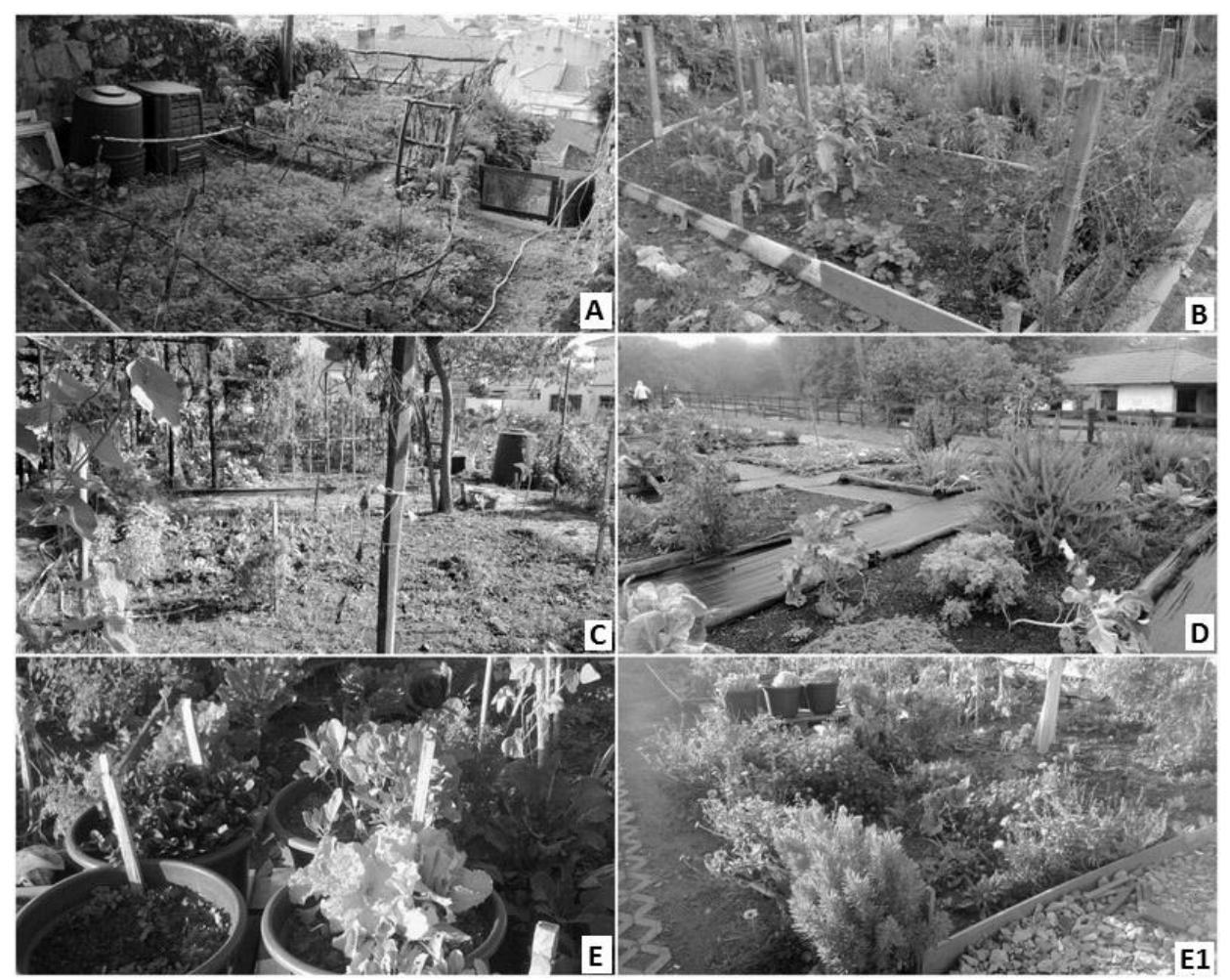

Figura 1 - A) Horta da Quinta Musas da Fontinha, B) Horta Nabos do Norte, C) Horta das Condominhas, D) Horta Clubes da Natureza, Serralves, E e E1) Hortas da Lada 1 e 2. Foto: Alessandra Araújo (2013).

O Plano Director Municipal, doravante PDM, se dá sobre o abrigo do Regime jurídico dos instrumentos de gestão territorial (RJIGT), e é regulamentado por legislação específica, a qual descreve os princípios dos planos municipais e os quais os planejadores devem seguir. Esse regulamento prevê e define categorias e subcategorias de uso do solo que são dividas entre o chamado "solo urbanizado" e "solo afeto à estrutura ecológica". A estrutura ecológica (EE), segundo Ferreira, é um instrumento do planejamento ambiental e de ordenamento do território que tem a função de conduzir o uso antrópico nesse último (FERREIRA, 2010). Ela

tem como objetivos a preservação e a promoção das componentes ecológicas e ambientais do território concelhio, assegurando a defesa e a valorização dos elementos patrimoniais e paisagísticos relevantes, a proteção de zonas de maior sensibilidade biofísica e a promoção dos sistemas de lazer e recreio. Artigo 420, 1 . Regulamento do PDM, 2012.

A metodologia aplicada à estrutura ecológica a divide em duas categorias, a EE principal, e a EE secundária. Segundo Magalhães, a EE principal tem a função de proteger recursos naturais, ao mesmo tempo em que se liga à construção de uma estrutura biológica nas cidades - entendida aqui por incentivo à promoção da biodiversidade -, assim, para o 
autor, as hortas urbanas se encaixariam nessa categoria (MAGALHÃES, 1991 apud LEITE, 2012). Já de acordo com Ferreira, a EE secundária visa dar suporte e garantir processos ecológicos em áreas edificadas e servir como proteção ao meio biofísico em áreas privadas. As hortas urbanas, segundo o autor, seriam parte integrante dessa estrutura, juntamente aos vazios urbanos, áreas livres de proteção às infraestruturas, etc. (FERREIRA, 2010). Entretanto, cabe aqui ressaltar que essa possibilidade das hortas urbanas integrarem a EE, seja ela primária ou secundária, não é mencionada no regulamento do plano diretor. Não há no regulamento, e de forma geral, não há o reconhecimento legal das atividades de AU na legislação Portuguesa como um todo, assim, formalmente e claramente, a atividade é omitida dos planos de urbanização dos municípios, como acontece em Porto (GONÇALVES, 2013).

Para além da EE, o PDM do Porto define outras áreas que poderiam ser inseridas na perspectiva de um zoneamento ambiental, são elas a Reserva Agrícola Nacional (RAN) e a Reserva Ecológica Nacional (REN). A RAN é um instrumento de gestão territorial de restrição de utilidade pública de âmbito nacional, e trata do conjunto das áreas que apresentam aptidão agrícola, considerados seus fatores climáticos, geomorfológicos e pedológicos. Seu emprego é aplicado apenas ao solo rural e não aos que integram o que o PDM determina como solo urbanizado ou urbanizável. Além disso, não integra ou sobrepõe o solo correspondente à estrutura ecológica. A REN, por sua vez, é definida como uma estrutura biofísica que, dada suas características ecológicas especiais, deve ser preservada a fim de garantir a proteção de ecossistemas e dos processos biológicos que dão suporte ao equilíbrio das atividades humanas. Tem, como alguns de seus objetivos, a proteção dos recursos hídricos e pedológicos, a prevenção de inundações, erosões, cheias, etc., de forma que promova a sustentabilidade ambiental e a proteção de pessoas e bens (Regulamento do PDM, 2012).

Madureira, Andresen e Monteiro (2011) relatam que somente em 1954 a cidade do Porto produziu o seu primeiro instrumento de planejamento, não sendo o desenvolvimento da cidade antes desse período guiado por qualquer outra estratégia qualificada para tal. Além disso, as autoras mencionam que foram somente o Plano Regulador da Cidade do Porto (1947-1954) e o Plano Director Municipal implantado em 2006, e ainda em curso, que se atentaram de maneira mais compreensiva sobre a estrutura verde urbana, no que tange à necessidade dela possuir características como conectividade e multifuncionalidade. Ressaltam que foi principalmente este último que apresenta tais perspectivas através da reformulação da carta de uso do solo e da inclusão das áreas verdes e da estrutura ecológica. Segundo as autoraa o PDM define a reabilitação de espaços públicos e a necessidade de os ambientes construídos adotarem uma visão sistemática sobre os recursos ecológicos, representando um avanço na delimitação da estrutura ecológica municipal e em outras áreas que concernem às preocupações ambientais (MADUREIRA; ANDRESEN; MONTEIRO, 2011). 
A Figura 2 ressalta outros fatores observados nas entrevistas e no Regulamento do PDM e sintetiza a análise antes detalhada, fazendo entender qual a relação da AU - no que concerne aos casos estudados especificamente - e o plano diretor da cidade.

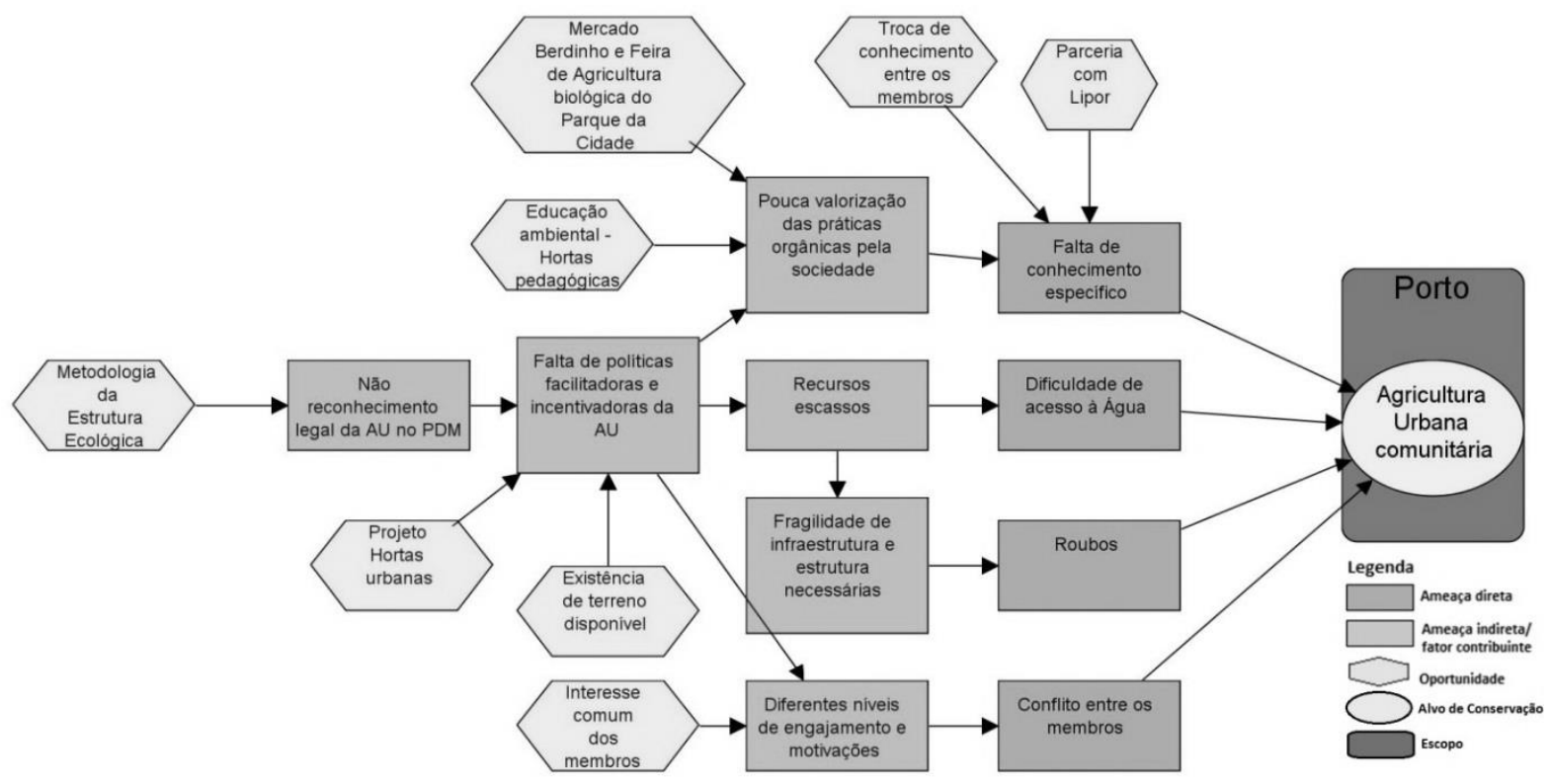

Figura 2 - Cadeia de resultados: PDM e AU em Porto. Elaboração própria com o uso do Software Miradi versão 4.1.3.

São feitas quatro considerações principais sobre o cenário observado da $A U$ no Porto e sua relação com o PDM. Primeiramente pode-se dizer que uma vez surgida por aspirações distintas e se perpetuar por diferentes níveis de engajamento, o auxílio ao "movimento" da AU pelo PDM se torna uma tarefa difícil, já que este não pode ser feito generalizando o significado final da AU no município. Porém, e em segundo lugar, tal reconhecimento é importante para incentivar a ligação entre o que é feito pela AU a nível local e o que é desejado para as cidades no que se relaciona ao alcance de sua sustentabilidade, ao contrário do que vem sendo notado, em um cenário em que as práticas que poderiam se juntar a uma visão globalizada estão restringidas. Isto é, o reconhecimento pelo PDM corrobora os potenciais da AU ao mesmo tempo em que reforça seus próprios objetivos. Assim, haveria o estabelecimento de uma relação entre os objetivos de desenvolvimento socioambiental do plano, os aspectos que as pessoas gostariam de ver melhorados nas cidades e o que já é exercido na prática. Em terceiro lugar, a forma como os entrevistados pensaram a $\mathrm{AU}$, e justamente por tal descolamento antes referido, fez parecer que sua transformação em uma política específica do planejamento não é necessária, e talvez apenas merecedora de incentivos pontuais, como algum programa específico, por exemplo, o que inclusive já vem sendo feito pela Câmara, 
através de uma parceria com a Lipor ${ }^{3}$. Por último, deve-se ressaltar a potencialidade do PDM de implementar tal política, uma vez que esse já possui a "metodologia" da Estrutura Ecológica, o que seria uma forma de incluir as práticas de AU no território. Assim, a EE ao mesmo tempo em que alimentaria as práticas de AU seria alimentada por essa, tendo em vista a confluência de finalidades e capacidade de ambas. Ademais, essas pontuações são reforçadas por Leite, que, quando tratando da localização da AU nas cidades, diz:

A escolha do local [de implantação das hortas] deve passar inicialmente pela consulta do PDM da câmara municipal, uma vez que nele constam informações sobre a capacidade do uso do solo, a sua aptidão agrícola e florestal e a definição de Estrutura Verde Urbana, a delimitação das áreas aptas e necessárias à expansão urbana, as restrições que afetam o uso do solo, designadamente a RAN, a REN bem como o domínio público hídrico e a sua articulação funcional com a Estrutura Verde Principal. [...] É com base no PDM e no PU [Plano de urbanização], a autarquia deve fazer uma seleção dos locais que mais se adequam à implementação da horta urbana (LEITE, 2012:19).

\section{5. "Plano Diretor", "Plano Diretor de Desenvolvimento Integrado" e hortas em Belo Horizonte}

As entrevistas revelaram que as iniciativas de AU comunitária em Belo Horizonte apresentaram como principais motivações a segurança alimentar e nutricional conjugada com o envolvimento da comunidade vizinha na atividade, o aumento da renda, a limpeza de determinado terreno e a oportunidade de exercer, através das hortas, uma atividade de lazer. A segurança alimentar está relacionada à garantia de acesso a uma dieta mais saudável e diversa, e juntamente à possibilidade de incremento da renda familiar, foi a motivação mais frequentemente apontada pelos entrevistados para a referida prática, tendo um peso maior sobre as demais. Conjuntamente, as iniciativas têm como visão, portanto, um cenário no qual as famílias da comunidade tem simultaneamente acesso a uma alimentação mais saudável e o aumento de sua renda. Apesar de terem identificado oportunidades iniciais que contribuíram para o estabelecimento das hortas - como os cursos de capacitação oferecidos, o interesse de alguns atores pontuais em ajudá-los, o interesse da comunidade em se envolver com os projetos, a necessidade iminente de incrementar a renda e a alimentação-, eles demonstraram dificuldades em apontar atuais oportunidades que auxiliam na continuidade do projeto.

\footnotetext{
${ }^{3}$ A Lipor - Serviço Intermunicipalizado de Gestão de Resíduos do Grande Porto - é uma empresa pública, resultado da associação dos municípios portugueses de Espinho, Gondomar, Maia, Matosinhos, Porto, Póvoa de Varzim, Valongo e Vila do Conde, que realiza a reciclagem, valorização, tratamento e aproveitamento final dos resíduos sólidos das cidades associadas. A empresa possui o Projeto Horta à Porta, na qual oferece treinamentos sobre agricultura biológica e compostagem aos interessados. No Porto, os terrenos para a implantação das hortas são cedidos pela câmara municipal sem custo para os usuários, que devem obedecer a determinadas exigências. Ver http://www.lipor.pt/.
}

(c) Urbana: Rev. Eletrônica Cent. Interdiscip. Estud. Cid Campinas (SP) V.8, n.2 [13] $\quad$ p.190-209 ISSN 1982-0569 
Identificaram, entretanto, ameaças tanto iniciais como em curso que poderiam comprometer seu andamento. Apesar de ser considerado um desafio na região, os entrevistados não mencionaram ser o acesso à água uma ameaça às atividades, como se pode notar através da Figura 3 a seguir, na qual estão pontuadas as principais ameaças e oportunidades identificadas pelos entrevistados à permanência das suas práticas, assim como feito para o caso do Porto.

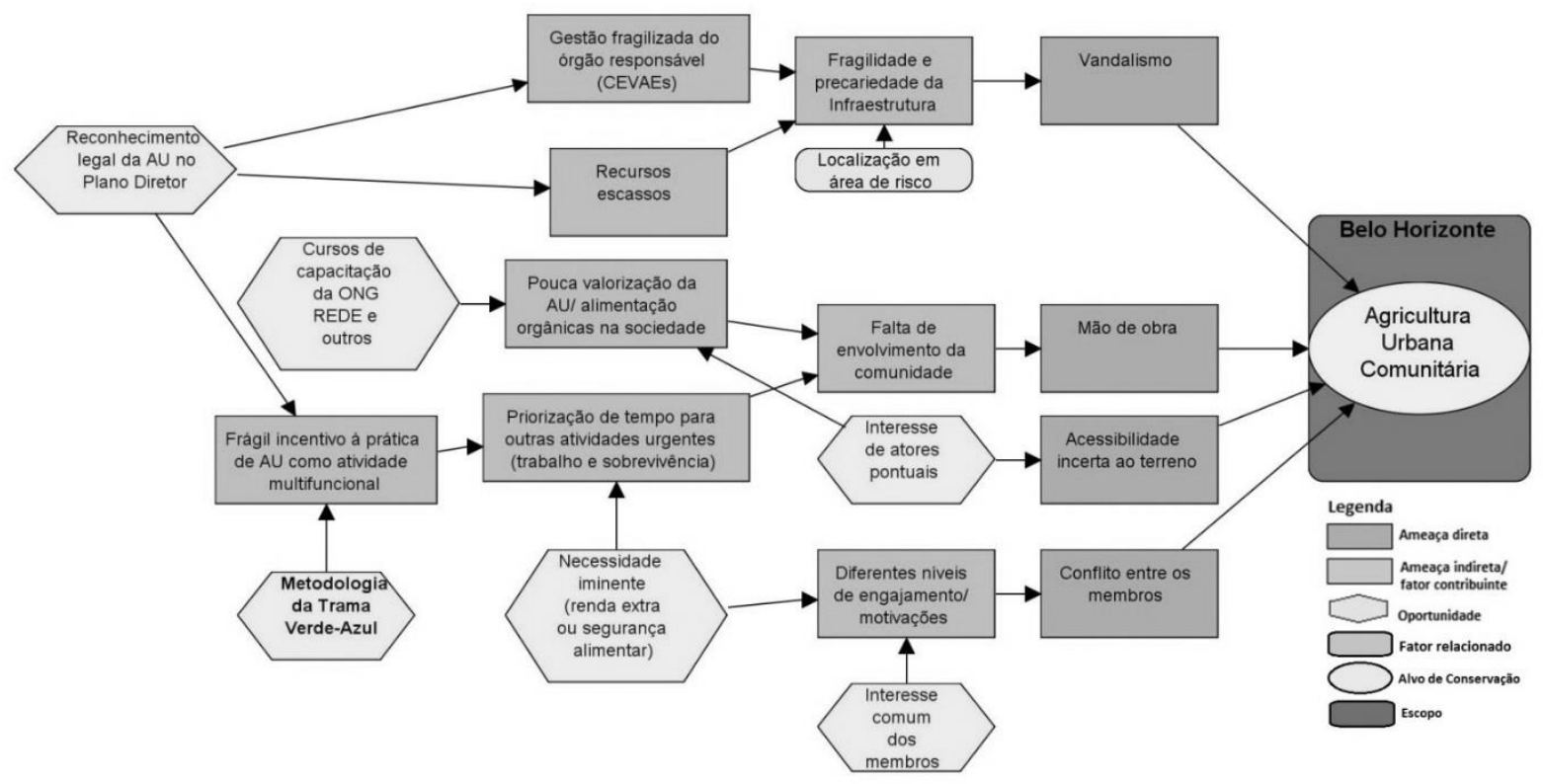

Figura 3 - Cadeia de resultados: PDDI e AU em Belo Horizonte. Elaboração própria com o uso do Software Miradi versão 4.1.3.

Diferentemente da maioria das hortas em Porto, em Belo Horizonte apenas duas das iniciativas estudadas apresentaram em algum período do tempo outro projeto que tivesse finalidade similar à da $A U$, e atualmente esse já não existe mais. Assim, a $A U$ foi, como mencionado, uma oportunidade única e necessária tendo em vista os objetivos que queriam alcançar e as necessidades iminentes com as quais os agricultores se depararam. $\mathrm{O}$ apoio da prefeitura às hortas foi mencionado quando as iniciativas eram parte de algum programa governamental: o caso dos $\mathrm{CEVAEs}^{4}$, ou quando parte da produção da horta era destinada ao abastecimento da merenda escolar. Nos demais casos o apoio aos agricultores foi feito por atuação de ONGs, principalmente da REDE, e outros grupos não governamentais.

A ONG REDE (Rede de Intercâmbio de Tecnologias Alternativas) é considerada uma agente chave em toda a história e formação das hortas estudadas e aparentemente nas demais iniciativas comunitárias relacionadas à agricultura e desenvolvimento sustentável

\footnotetext{
${ }^{4}$ Os CEVAEs são Centros de vivência agroecológica dados inicialmente através de uma parceria entre poder público, por meio das Secretarias Municipais de Abastecimento, de Meio Ambiente, de Saúde, de Educação e de Assistência Social, e a sociedade civil, nomeadamente aquela urbana periférica e a ONG Rede de Intercâmbio de Tecnologias Alternativas (COUTINHO, 2007). O projeto viabiliza, através de gestão compartilhada e participativa, a ocupação produtiva de áreas verdes urbanas. Atualmente os CEVAES são geridos e de responsabilidade da Fundação de Parques Municipais.
}

(c) Urbana: Rev. Eletrônica Cent. Interdiscip. Estud. Cid Campinas (SP) V.8, n.2 [13] $\quad$ p.190-209 ISSN 1982-0569 
conhecidas na cidade. Fundada em 1986, a REDE tem se inserido no discurso sobre agroecologia, segurança alimentar, agricultura urbana, e outros na região de Belo Horizonte, estabelecendo diálogo constante com a sociedade civil e o poder público. É em parceria com a Prefeitura de Belo Horizonte (PBH), e atuando como representante da sociedade civil, que a ONG inicia um trabalho na cidade de incentivo à promoção de práticas de $A U$ em parâmetros agroecológicos, marcadamente através de sua inserção no projeto "Cidades Cultivando para o

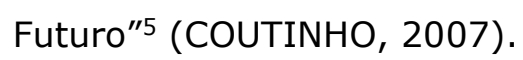

Um fator a ser ressaltado sobre o cenário da prática da AU em Belo Horizonte, é o fato de as iniciativas acontecerem em áreas urbanas periféricas, caracterizadas pela baixa renda dos moradores e pelo déficit de acesso aos serviços e infraestrutura urbana - devido à sua localização desprivilegiada em relação à área central. Em alguns casos podem estar instaladas em áreas de risco - dado, entre outros fatores, à declividade do terreno -, configurarem alguma predação ambiental - por ocuparem áreas de interesse ambiental-, fazerem parte da chamada cidade ilegal ${ }^{6}$, e por isso, conviverem com situações de ocupações e irregularidades urbanas diversas. Esse fato certamente deve ser relacionado ao surgimento das atividades de AU locais, já que aponta para uma realidade social, econômica e ambiental que deve ser ponderada quando do reconhecimento da real necessidade e importância da AU para esses moradores, e analisada no momento da formulação de políticas específicas voltadas paras essas questões. Pode-se afirmar que a ocorrência de $\mathrm{AU}$ em $\mathrm{BH}$ - tendo em vista a existência da cidade ilegal e o que ela aponta sobre as práticas do planejamento locais-, representa uma forma de resistência destes moradores à forma como a produção e reprodução da vida na cidade vem Ihes sendo permitida. A AU no contexto desta cidade mostra-se como expressão socioespacial da realidade econômica e ambiental que a população apresenta, revelando-se como a materialização de demandas de uma camada específica da população.

5 O Programa Cidades Cultivando para o Futuro (CCF) foi implantado pela ONG Internacional RUAF e cofinanciado por organizações Holandesa (DGIS) e Canadense (IDRC). "Em Belo Horizonte, cidade piloto brasileira, o programa CCF tem como meta a identificação das iniciativas e potenciais da AU. [...] Especificamente, o programa visa à criação de um Fórum municipal de discussão sobre a AU e a implantação de uma experiência piloto. Esse fórum deverá se constituir em uma instancia capaz de criar estratégias de convencimento ao governo local de que a AU é uma possível ferramenta promotora de gestão urbana-ambiental. O resultado, enquanto meta do CCF, deve ser a formulação de uma lei municipal da AU" (COUTINHO, 2007).

${ }^{6}$ Segundo Costa (2006) a cidade ilegal é a contraposição à cidade legal, essa última, do ponto de vista urbanístico, é a cidade construída pelo mercado imobiliário ou outro agente formalmente instituído, é projetada, apresenta ordem urbanística, e na qual os itens de consumo coletivo, serviços e equipamentos, estão presentes. Para a autora, a ilegalidade atinge de forma mais perversa aos pobres, não se restringindo apenas a esses, e deve ser distinguida entre a ilegalidade como consequência da necessidade dada a impossibilidade de "cumprir com as imposições da cidade mercadoria" e aquela resultante da intenção expressa de infringir a lei (COSTA, 2006).

(c) Urbana: Rev. Eletrônica Cent. Interdiscip. Estud. Cid Campinas (SP) V.8, n.2 [13] $\quad$ p.190-209 ISSN 1982-0569 

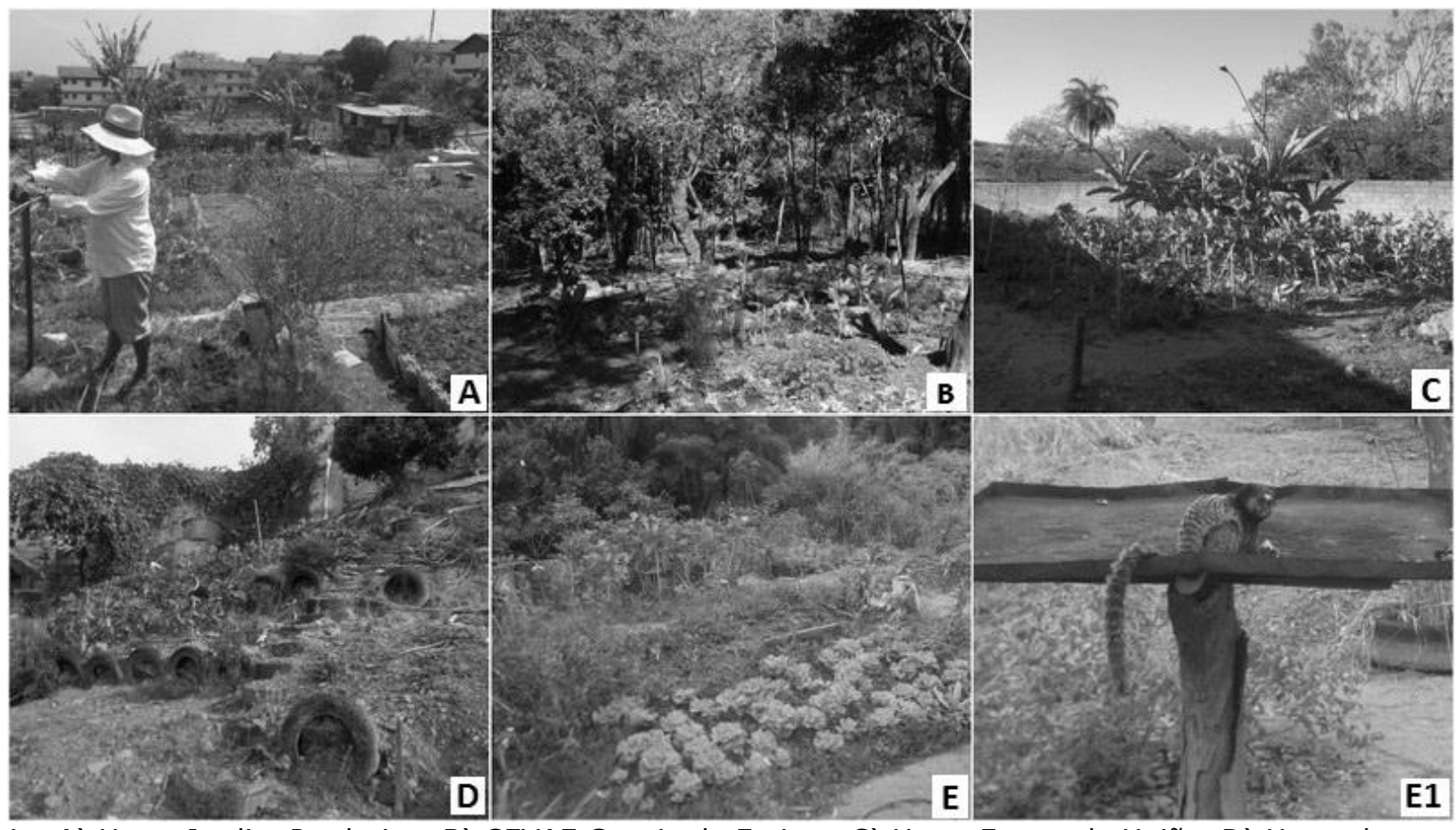

Figura 4 - A) Horta Jardim Produtivo, B) CEVAE Granja de Freitas, C) Horta Frutos da União, D) Horta do Cafezal, E e E1) CEVAE Capitão Eduardo. Fotografias autorais.

Na atual Lei No 9.959/2010 que institui o Plano Diretor e estabelece normas e condições para parcelamento, ocupação e uso do solo urbano no município, respectivamente, a AU já é incluída como categoria possível do solo urbano, o que certamente é ação principal para o seu reconhecimento e o endereçamento de políticas que a estimule. Segundo Coutinho (2007), apesar de a AU ser um fenômeno legitimado pela legislação, tal reconhecimento é fragilizado pelas dificuldades que a $\mathrm{AU}$ apresenta em se tornar uma ferramenta no combate à pobreza e à fome locais. Para a autora, isso se dá, dentre outros fatores, pelo fato de não ter sido encontrado nenhum conceito que definisse a $\mathrm{AU}$ e o público que se beneficiaria das políticas a ela dirigidas no plano diretor da cidade (COUTINHO, 2007).

O Plano Diretor de Desenvolvimento Integrado da Região Metropolitana de Belo Horizonte, doravante PDDI, consolida-se como um plano de gestão do território metropolitano que integra uma nova proposta de Sistema de Gestão Metropolitana do Estado de Minas Gerais (PDDI, 2011). Sua elaboração teve início em 2004, e é somente com sua elaboração, após trinta anos de existência da região metropolitana de $\mathrm{BH}(\mathrm{RMBH})$, que a sociedade civil passa a fazer parte do Concelho Deliberativo responsável por aprovar o plano em questão (PDDI, 2011). Assim, o PDDI não é voltado apenas para $\mathrm{BH}$, mas busca orientar a gestão de toda a $\mathrm{RMBH}$, através da proposição de políticas e programas que possam satisfazer as demandas econômicas, sociais, ambientais e territoriais da região. Um dos eixos temáticos que orienta a formulação de tais políticas e projetos é o eixo chamado Seguridade, que tem o objetivo de garantir segurança aos cidadãos nas dimensões alimentar, posse da terra e moradia, trabalho e renda (PDDI, 2011). Integrando cada Eixo Temático estão as Áreas Temáticas, que se 
voltam a assuntos específicos, como a "CEAT - Cultura, educação, alimentação e trabalho", área em que podem ser encontradas as questões relativas à AU. Assim, a AU é inserida em um contexto que se relaciona à cultura, ao trabalho, à alimentação e à educação, conseguindo, portanto, abordar grande parte das questões que essa prática perpassa. A AU é definida no PDDI como

um conjunto de práticas (produção-extração-transformação-comercialização) e serviços com potencial para: disponibilizar espaços públicos e privados para uso produtivo e coletivo (provisório); favorecer a construção de redes de vizinhança (sociabilidade), o lazer, trabalho próximo ao ambiente doméstico e trocas monetárias e não monetárias; melhoria da qualidade ambiental - paisagismo, sombreamento, clima local, impermeabilização do solo, ciclos hidrológicos, ciclagem de nutrientes; melhorar a segurança pública através da requalificação ambiental e uso de lotes vagos; serviços de limpeza urbana através da eliminação de vetores nocivos à saúde humana, aproveitamento integral de alimentos (educação alimentar), uso de resíduos sólidos para contenção de canteiros e compostagem orgânica e uso de resíduos líquidos (água servida) para irrigação. (PDDI, 2009).

Ademais a definição acima, o PDDI expõe alguns planos, programas ou projetos que se relacionam à promoção da $\mathrm{AU}$, como por exemplo, os "Centros de Apoio à Agricultura Urbana e Peri Urbana em regiões metropolitanas (CAUP-BH)", o "Programa Centro de Vivência Agroecológica - CEVAE (1996) - PBH", o "Programa Agricultura Urbana/Minas sem Fome Estado de Minas Gerais", etc. (PDDI, 2009).

Considerando a existência dos marcos acima (programas, projetos, planos e reconhecimento legal da AU no PDBH e no PDDI), e os fatores apontados nas entrevistas, pode-se intuir que outras considerações corroboram o argumento de Coutinho (2007) sobre a fragilidade da legislação competente em tratar a AU na cidade. Na abordagem desse trabalho, no qual se considera a relação entre as hortas na cidade e a busca pela sustentabilidade através da implantação de planos diretores, a fragilidade encontrada em $\mathrm{BH}$ não diz respeito apenas, como abordado por Coutinho (2007), às questões relacionadas à fome e pobreza. Primeiramente deve-se reconhecer que o cenário de surgimento e perpetuação da $A U$, como já revelado pelas entrevistas, faz jus à forma como o planejamento da cidade vem a tratando, como matéria de responsabilidade principalmente dos órgãos de assistência social e alimentação. Esse fato pode ser revelado pela sua inclusão como atividade de economia solidária, e, portanto, apoiada pela Secretaria de Políticas Sociais, e como uma atividade basicamente promotora do abastecimento alimentar, e não potencialmente promotora de desenvolvimento local (COUTINHO, 2007). Assim, tendo em vista o meio em que surge, o tratamento da AU pelo PDDI é funcional às demandas da população. Entretanto, para que a atividade seja integrante de uma política de sustentabilidade do território, alguns desafios ainda se mostram presentes. 
Assim como mostra a Figura 3 o surgimento e perpetuação de práticas de AU ainda é comprometido, o que corrobora a denúncia de que tal gestão da atividade é ainda incipiente. Para que ela se apresente como uma ferramenta de alcance da sustentabilidade na cidade é preciso que para além da sua real funcionalidade alimentar e econômica, o planejamento urbano local se atente para a multifuncionalidade dessa prática, utilizando-a como ponte ao planejamento ambiental. O meio em que surgem as hortas comunitárias em $\mathrm{BH}$ vem sendo identificado e trabalhado corretamente pelo poder público, uma vez que esse último se voltou para dimensão que a $A U$, da maneira até então exercida, pretendeu alcançar. Por outro lado, quando se reconhece que os benefícios da AU ultrapassam os de segurança alimentar e incremento da renda, novos esforços são necessários para fazer com que essa atividade integre uma aspiração sobre a sustentabilidade de forma mais ampla. Nesse sentido, esses novos esforços estariam em fazer a AU se ligar à prática do planejamento ambiental.

A proposta de construção de uma "Trama Verde-Azul", uma das aspirações do PDDI diante do objetivo de promover uma reorganização do território metropolitano, se mostra como uma oportunidade que corroboraria a inclusão das hortas urbanas no planejamento ambiental de caráter multifuncional. A Trama Verde-Azul estabelece espaços multifuncionais que tem potencial em proteger atributos ambientais e paisagísticos da RMBH, conectando áreas de importância cultural e socioambiental (PDDI, 2014). A metodologia, que é de inspiração francesa, articula cursos d'agua, barragens e lagoas com um sistema de áreas protegidas e parques lineares urbanos, valoriza a natureza na RMBH através do sistema viário, dos grandes vales, áreas de proteção, parques lineares urbanos nas áreas mais adensadas, atividades de lazer, educação e habitação social. Além disso, usa como principais elementos para essa articulação as principais bacias hidrográficas de $\mathrm{BH}$ e os cursos d'agua. Embora a AU seja incluída como uma de suas atividades componentes, juntamente às de lazer e turismo, a própria definição da Trama como uma metodologia que se sobrepõe à divisão territorial coloca dificuldades em ser funcional à promoção da AU em Belo Horizonte. Isto é dito justamente pelo fato de as hortas comunitárias ocorrerem em porções dispersas e escalas reduzidas do território, e recorrentemente estarem desvinculadas dos grandes Centros Ambientais Culturais, os quais a Trama Verde-Azul busca integrar objetivamente. A existência da metodologia da Trama Verde-Azul é de fato um avanço nas práticas do planejamento ambiental metropolitano, mas é necessário conceber planos mais pormenorizados no mesmo sentido que este para cada cidade que a metodologia engloba a fim de que a integração da $A U$, como atividade multifuncional e dinâmica que é, seja efetivamente abarcada pelo plano municipal.

\section{Porto e Belo Horizonte: convergências, semelhanças e possibilidades}

Fazendo uso das categorias de Quon (1999), definidas sob o tipo de postura que as cidades apresentam em relação à agricultura urbana, pode-se incluir a gestão da cidade do Porto como "neutra", e a de Belo Horizonte como "positiva" em relação à atividade. A definição 
da segunda cidade como positiva se faz pelo reconhecimento da AU como uma categoria legal e possível de uso do solo, diferentemente da primeira cidade, onde a prática apesar de não ser desestimulada - uma vez identificadas determinadas oportunidades ao seu desenvolvimento-, não é também encorajada, justamente pela sua não inclusão como uma categoria de uso do solo.

Notou-se certa diferenciação entre a motivação para a AU nas cidades em estudo. Enquanto em Porto o envolvimento com a atividade mostrou ampla finalidade, em Belo Horizonte se restringiu basicamente à segurança alimentar e à possibilidade de incremento da renda familiar. Essa diferenciação demonstra uma perspectiva diferenciada sobre a AU pelos atores que a produzem, o que faz com que os planos oficiais de gestão do território também as englobem de forma diferenciada. Surgida de uma demanda social mais urgente, a AU em BH mostrou mais força em ser merecedora de uma política que a contemple. Intui-se que quando sua prática não se ligou a uma demanda social de caráter urgente, como algumas características das práticas do Porto apontam, essa inclusão como política é da mesma forma não considerada iminente. Para esse fato, defende-se aqui que não apenas a dimensão social da AU deve ser levada em conta pelos planos diretores, mas também seu caráter multifuncional, já que ele pode ser usado de forma a corroborar as expectativas de desenvolvimento local tidas pelos planejadores. É nesse sentido que o planejamento ambiental deve ser aplicado, possibilitando uma ligação entre os benefícios da AU e o objetivo do planejamento em construir cidades mais sustentáveis.

Percebeu-se que a cidade do Porto possui potencial para exercer a prática do planejamento ambiental englobando a AU como parte da Estrutura Ecológica, metodologia já existente e bem estruturada. Já em $\mathrm{BH}$ a metodologia da Trama Verde-Azul ainda oferece limitações para um plano de pormenor que busque tal inclusão. Certamente a elaboração da Trama Verde-Azul já é um avanço tendo em vista a inexistência, até o começo de elaboração do PDDI, de uma metodologia que proponha uma abordagem multifuncional a ser aplicada no território, como essa propõe. Assim, ambas as cidades já possuem encaminhamentos que possam trabalhar para a inclusão da AU de forma mais eficiente nos planos oficiais, seja pela maior força de sua prática de planejamento ambiental ou pelo reconhecimento da funcionalidade da AU para a população que a pratica.

A postura apresentada por cada cidade de acordo com as categorias sugeridas por Quon, acima relatadas, sugere mais duas considerações. Primeiramente pode-se intuir que a forma espacial das hortas, ou seja, sua distribuição no território, é de fato parcialmente resultante do tratamento que elas vêm recebendo do plano oficial, reforçam a finalidade de sua realização em cada cidade, e revelam distintas ausências sentidas pelos que a praticam. Em Porto, as hortas não obedecem a uma tendência de distribuição, estando localizadas tanto no centro histórico como no limite do município, revelando e implicando na distinção entre as formas pelas quais se dão e entre os atores que a praticam, o que faz enfraquecer a 
possibilidade de sua inclusão pelo planejamento. Assim, as inciativas vão se reproduzindo no território de forma não planejada e aleatória. Em BH essas hortas acontecem na periferia, onde as necessidades e situação dos moradores são conhecidas e de certa forma mais homogêneas. Isso faz com que sua incorporação no planejamento seja mais concreta e reclamada, o que resulta em um apoio do plano às hortas periféricas e por isso elas tendem a se reproduzir dentro de uma mesma tendência espacial. Ou seja, a distribuição territorial das hortas nas duas cidades parece estar relacionada fortemente à forma de sua relação com planejamento.

A segunda consideração se faz sob o que Boaventura de Sousa Santos denominou Sociologia das Ausências e Sociologia das Emergências (SANTOS, 2004). Ambos os conceitos são o resultado de uma reflexão epistemológica do autor que tenta combater o que ele chamou de "desperdício da experiência social". A Sociologia das Ausências visa, pela demonstração de que a experiência não existente é objetivamente produzida como tal pela ciência convencional, ampliar o mundo e dilatar o presente. Por outro lado, a Sociologia das Emergências busca uma consciência antecipatória sobre as possibilidades existentes de satisfação de determinada carência, mas que devido a certos motivos não é considerada. Ou seja, a primeira busca fazer com que as iniciativas já existentes sejam consideradas alternativas virtuosas às experiências hegemônicas, e a segunda, ao buscar uma relação mais equilibrada entre experiência e expectativa, radicaliza experiências possíveis até então consideradas futuras e as assenta nas capacidades e possibilidades reais do presente (SANTOS, 2004). Essa discussão é feita para argumentar que tanto a prática da AU no Porto como em $\mathrm{BH}$, poderiam ser pensadas sob a forma de abordagem proposta por Santos.

Pode-se falar de um desperdício da experiência social ligada à AU nas duas cidades, mesmo de formas distintas. Na medida em que é existente a prática de AU no Porto e essa não é utilizada pelo planejamento de forma a fortalecer seus próprios objetivos, vê-se que a possibilidade de fazer uso de uma alternativa existente para a promoção da gestão sustentável do território está sendo desperdiçada. Neste ponto, pode-se falar que é aplicável a Sociologia das Ausências. Em Belo Horizonte, por outro lado, a prática de AU é aproveitada, mas limitada pela funcionalidade que é atribuída a ela pelo Plano Diretor. Assim, ao analisar a situação sob o prisma da Sociologia das Emergências, um esforço em destacar as potencialidades dessa prática em integrar demandas atuais de uso multifuncional do território deve ser feito de forma a aproveitar seu potencial, e não delegar ao futuro a exploração de benefícios que satisfazem carências já sintomáticas e percebidas.

\section{Conclusão}

Antes de derivar conclusões obtidas com base nos resultados apontados neste trabalho devem-se destacar algumas limitações colocadas a ele no decorrer de sua elaboração. Três principais limitações foram identificadas: a falta de acesso ao Plano Director Municipal do

(c) Urbana: Rev. Eletrônica Cent. Interdiscip. Estud. Cid Campinas (SP) V.8, n.2 [13] $\quad$ p.190-209 ISSN 1982-0569 
Porto, tendo a análise sobre a cidade se baseado na legislação de Regulamento do PDM, na literatura que tratou do assunto e nas informações disponíveis no website da Câmara do Porto; o reduzido número de publicações brasileiras ou em português sobre a temática deste trabalho, o que certamente enriqueceria a compreensão da situação local da $A U$; e o intervalo de tempo entre as entrevistas realizadas nas duas cidades, o que fez a pesquisa amadurecer ou reformular determinados objetivos que não poderiam ser retomados nas entrevistas já realizadas. Outro fator a se considerar é a ainda permanência das atividades ligadas à implantação do PDDI, que não possibilita a verificação da real eficácia de seus projetos e proposições.

As análises tidas neste trabalho permitiram avaliar que é ainda limitada a contribuição da AU nas cidades estudadas em consolidar um planejamento urbano de viés mais sustentável. Os principais desafios colocados a essa consolidação foram a não incorporação da AU como categoria de uso do solo ou o não reconhecimento de sua multifuncionalidade pelos planejadores. Apesar de indiscutivelmente benéficas à sociedade, ambiente e economia locais, a AU não parece corroborar até então, nos dois casos, os ideais de sustentabilidade nos planos oficiais de gestão do território.

A ponte entre a $\mathrm{AU}$ e o planejamento urbano feita através das práticas de planejamento ambiental mostrou-se incipiente nos casos de estudo, o que dificulta o objetivo do planejamento urbano em tornar-se um catalizador de uma cidade sustentável. A prática de planejamento ambiental no Porto, considerando-se a existência da metodologia da Estrutura Ecológica, mostra-se como oportunidade para a implantação de tal ponte, o que ainda é dificultado pelo seu não reconhecimento legal da Agricultura Urbana. Em Belo Horizonte, apesar de haver tal reconhecimento, o planejamento ambiental é fragilizado e não incorpora de forma eficaz as hortas comunitárias urbanas.

Trazer as experiências sociais aplicadas através da AU para os métodos de planejamento urbano utilizados pelos planos oficiais é uma maneira de trabalhar o que se entende pela sustentabilidade nos territórios. Enquanto essa atividade que é crescente, iminente, e benéfica ao ambiente e à sociedade for ignorada ou limitada pelos planos de ordenamento territorial, haverá um desperdício de oportunidades e experiências que poderiam consagrar a sustentabilidade urbana de forma plural, cidadã e justa.

\section{Referências}

BELO HORIZONTE (1996). Lei Municipal No 7.165, de 27 de Agosto de 1.996. Institui o Plano Diretor do Município de Belo Horizonte.

BELO HORIZONTE (2010). Lei Municipal No 9.959, DE 20 DE JULHO DE 2010. Altera as Leis $n^{\circ} 7.165 / 96$ e $n^{\circ} 7.166 / 96$, estabelece normas e condições para a urbanização e a regularização fundiária das Zonas de Especial Interesse Social, dispõe sobre parcelamento, ocupação e uso do solo nas áreas de Especial Interesse Social, e dá outras providências, 2010.

(c) Urbana: Rev. Eletrônica Cent. Interdiscip. Estud. Cid Campinas (SP) V.8, n.2 [13] $\quad$ p.190-209 ISSN 1982-0569 
COSTA, H.S.M (2006). A cidade ilegal: notas sobre o senso comum e o significado atribuído à ilegalidade. In: BRANDÃO, C. A. L. (org.). As cidades da cidade. Belo Horizonte: Editora da UFMG, p.145-156.

COUTINHO, Maura Neves. (2007). Agricultura urbana: análise e reflexão sobre os marcos legais e normativos no município de Belo Horizonte. Trabalho de conclusão de curso - Curso de Graduação em Geografia, Universidade Federal de Minas Gerais, Belo Horizonte.

FERREIRA, J.C. (2010). Estrutura ecológica e corredores verdes: estratégias territoriais para um futuro urbano sustentável. $4^{\circ}$ Congresso Luso-Brasileiro para o planejamento urbano, regional, integrado, sustentável. Universidade do Algarve. Faro, Portugal.

GONÇALVES, Sandra Cristina Santos. (2013). Agricultura urbana num contexto de crise: Um estudo de caso na Área Metropolitana do Porto. Dissertação de Mestrado Curso de Riscos, Cidades e Ordenamento do Território, Geografia, Universidade do Porto, Porto.

GÜNTHER, Hartmut. (2006). Pesquisa Qualitativa Versus Pesquisa Quantitativa: Esta É a Questão? Psicologia: Teoria e Pesquisa. V. 22 n. 2, p. 201-210.

LEITE, Inês Ariana dos Santos. (2012). Hortas Urbanas - dimensões ambiental e social. Dissertação de mestrado - Curso de Engenharia do Ambiente, Ambiente e Ordenamento, Universidade de Aveiro, Aveiro.

LIPOR - Serviço Intermunicipalizado de Gestão de Resíduos do Grande Porto. Disponível em <www.lipor.pt>. Acesso em: 23 Set. 2016

MADUREIRA, Helena; ANDRESEN, Teresa; MONTEIRO, Ana. (2011). Green structure and planning evolution in Porto. Urban Forestry \& Urban Greening, [s.I.], v. 10, n. 2, p.141149.

OLIVEIRA, Marcelo A. (2013). Hortas na malha urbana: história e perspectiva para o planejamento ambiental nas cidades. MG Biota. V.6, n.1. Belo Horizonte.

Plano Diretor de Desenvolvimento Integrado da Região Metropolitana de Belo Horizonte - PDDI/RMBH. Proposta de estudos referenciais e elaboração de estratégias de ação para o planejamento do desenvolvimento integrado da região metropolitana de belo horizonte: marco teórico-metodológico e plano de trabalho. Volume II: Cedeplar/UFMG. Belo Horizonte, 2009.

Plano Diretor de Desenvolvimento Integrado da Região Metropolitana de Belo Horizonte - PDDI/RMBH. Relatório de Definição das Propostas de Políticas Setoriais, Projetos e Investimentos Prioritários: Sumário Executivo. Cedeplar/UFMG. Belo Horizonte, 2011.

Plano Diretor de Desenvolvimento Integrado da Região Metropolitana de Belo Horizonte - PDDI/RMBH. Macrozoneamento da RMBH. Marco teórico metodológico e definição das áreas temáticas afetas ao interesse metropolitano. Produto I, 2014.

(c) Urbana: Rev. Eletrônica Cent. Interdiscip. Estud. Cid Campinas (SP) V.8, n.2 [13] $\quad$ p.190-209 ISSN 1982-0569 
PORTO, Republicação do Regulamento do Plano Diretor Municipal do Porto, 1.a Alteração, Anexo. Diário da República, 2.a série - N.0 207 - 25 de outubro de 2012.

QUON, Soonya. (1999). Planning for Urban Agriculture: A Review of Tools and Strategies for Urban Planners. Cities Feeding People Series. International Development Research Center. Report 28.

SANTOS, Boaventura de Sousa. (2004). Por uma sociologia das ausências e uma sociologia das emergências. In: SANTOS, Boaventura de Sousa (Org.). Conhecimento prudente para uma vida decente. São Paulo: Cortez, p.777-821, 2004.

SLOCOMBE, D. Scott. (1993). Environmental planning, ecosystem science, and ecosystem approaches for integrating environment and development. Environmental Management, [s.I.], v. 17, n. 3, p.289-303, 1993. 